\title{
Nickel-Catalyzed 1,2-Diarylation of Alkenyl Carboxylates: A Gateway to 1,2,3-Trifunctionalized Building Blocks
}

\author{
Joseph Derosa $^{\dagger \neq}$, Taeho Kang ${ }^{\dagger \neq}$, Van T. Tran ${ }^{\ddagger}$, Steven R. Wisniewski ${ }^{\S}$, Malkanthi K. Karunananda ${ }^{\ddagger}$, Tanner C. \\ Jankins ${ }^{\ddagger}$, Kane L. $\mathrm{Xu}^{\ddagger}$, and Keary M. Engle ${ }^{\ddagger *}$ \\ ${ }^{\ddagger}$ Department of Chemistry, The Scripps Research Institute, 10550 North Torrey Pines Road, La Jolla, California 92037, United States \\ ${ }^{\S}$ Chemical \& Synthetic Development, Bristol-Myers Squibb, 1 Squibb Drive, New Brunswick, New Jersey 08903, United States
}

Supporting

Information

Placeholder

\begin{abstract}
A nickel-catalyzed conjunctive cross-coupling of alkenyl carboxylic acids, aryl iodides, and aryl/alkenyl boronic esters is reported. The reaction delivers the desired 1,2diarylated and 1,2-arylalkenylated products with excellent regiocontrol. To demonstrate the synthetic utility of the method, a representative product is prepared on gram scale and then diversified to eight 1,2,3-trifunctionalized building blocks using two-electron and one-electron logic. Using this method, three routes toward bioactive molecules are improved in terms of yield and/or step count. This method represents the first example of catalytic 1,2-diarylation of an alkene directed by a native carboxylate functional group.
\end{abstract}

Alkene starting materials serve as ubiquitous chemical feedstocks that can be readily transformed in a variety of ways to build complex molecules. ${ }^{1}$ Transition-metal-catalyzed conjunctive cross-coupling has garnered widespread interest in recent years as a powerful tool for installing two different groups across a $\mathrm{C}-\mathrm{C} \pi$-bond. ${ }^{2}$ Traditionally, 1,2-diarylation methods have been largely limited to conjugated alkene substrates; in this case, after the key 1,2-migratory insertion event, the an electronically stabilized allyl or benzyl metal species is formed, from which $\beta$-H elimination is sluggish. ${ }^{3}$ In an effort to expand this mode of reactivity to unactivated, nonconjugated alkenes, our lab and other groups have employed an auxiliary-based chelation control strategy to stabilize the analogous alkyl metal intermediate as a metalacycle. ${ }^{4}$ Specifically, our laboratory has developed a suite of modular nickel-catalyzed alkene 1,2-difunctionalization reactions, in which reactivity and selectivity are facilitated by an 8 -aminoquinoline (AQ) amide-based bidentate auxiliary through the presumed intermediacy of 5- and 6-membered nickelacycles. ${ }^{4 a,} 5$ Practically speaking, the necessity for installation and removal of the AQdirecting group greatly diminishes the synthetic utility of such methods, requiring at least two concession steps (Scheme 1A).
Recently, we developed a nickel-catalyzed 1,2-diarylation reaction with a diverse array of simple alkenyl amides using dimethyl fumarate (DMFu) as ligand, which obviates the need for strong directing group and enables native amide groups to serve as efficient directors in conjunctive cross-coupling (Scheme 1B). ${ }^{6}$ We reasoned that the utility of this chemistry could be enhanced if other functional groups commonly encountered in synthesis could serve as directing groups. ${ }^{7}$ Given the versatility of carboxylic acids as diversifiable starting materials and their abundance as chemical feedstocks, we envisioned that the development of a carboxylate-directed ${ }^{10} 1,2$ diarylation of alkenes would be synthetically enabling. Hence, the goal of the present study was to demonstrate the feasibility of using free alkenyl carboxylic acid starting materials in nickel-catalyzed conjunctive cross-coupling (Scheme 1C).

\section{Scheme 1. Background and Synopsis of Current Work}

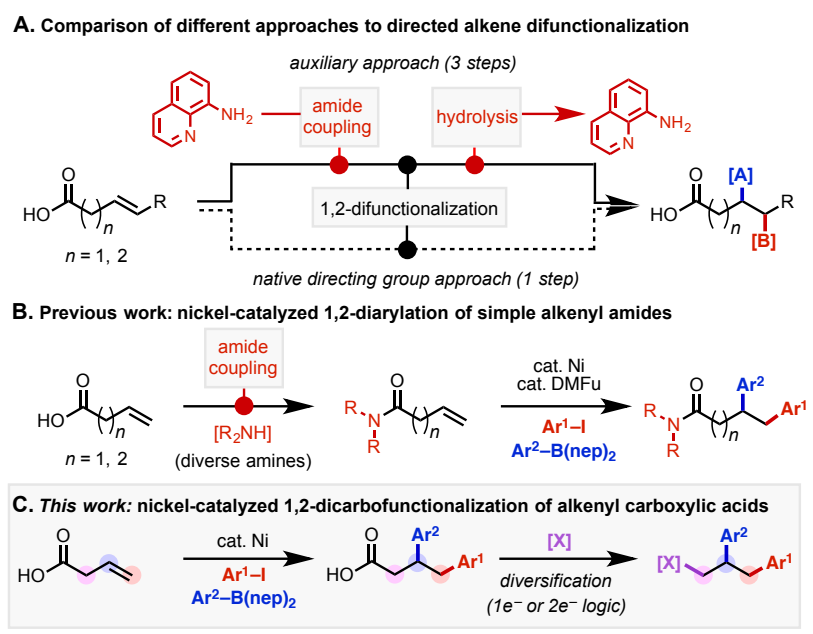

Table 1. Optimization of Reaction ${ }^{a}$ 


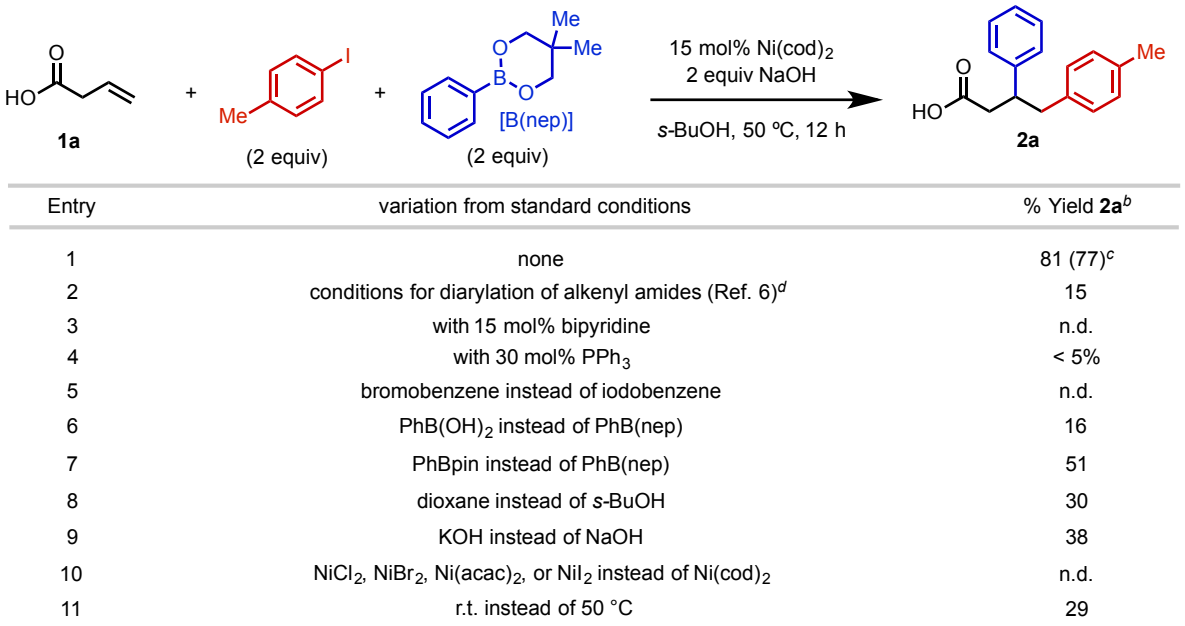

${ }^{a}$ Reaction conditions: $1 \mathrm{a}(0.1 \mathrm{mmol}), 0.1 \mathrm{M} s-\mathrm{BuOH} .{ }^{b}$ Percentages represent ${ }^{1} \mathrm{H}$ NMR yields using $\mathrm{CH}_{2} \mathrm{Br}_{2}$ as internal standard; n.d. = not detected. Values in parentheses are isolated yields. ${ }^{d}$ Reaction conditions: 15 mol\% Ni(cod)2, 15 mol\% dimethylfumarate, 1.5 equiv ArI, 1.5 equiv ArB(nep), 2 equiv $\mathrm{NaOH}, 0.1 \mathrm{M} i-\mathrm{BuOH}$ at r.t.

To initiate our investigation, we elected to use 3-butenoic acid $\mathbf{1 a}$ as our standard substrate, with 4-iodotoluene and phenylboronic acid neopentyl glycol ester ( $\mathrm{PhB}(\mathrm{nep}))$ as coupling partners, and $\mathrm{Ni}(\mathrm{cod})_{2}$ as the precatalyst (Table 1$)$. After extensive optimization, we were able to identify "ligandfree" conditions that delivered the desired product in $77 \%$ isolated yield (entry 1). Key findings were that sterically bulky secondary and tertiary alcohol solvents were beneficial, metal hydroxide bases (particularly with sodium as the countercation) led to enhanced reactivity, and neopentyl glycol boronic esters outperformed other organoboron nucleophiles. Under our previously published reaction conditions for simple alkenyl amide substrates, the desired product could be detected in only $15 \%$ yield with $\sim 20 \%$ Mizoroki-Heck product and $\sim 10 \%$ hydroarylation product (entry 2 ). Interestingly, the use of commonly employed ancillary ligands such as bipyridine and triphenylphosphine resulted in only Mizoroki-Heck byproducts and Suzuki-Miyaura biaryl formation with trace amount of desired product (entries 3 and 4). Aryl bromides were found to be incompetent coupling partners (entry 5). The corresponding free boronic acid gave the product in low yield, while the pinacol boronic ester reacted in moderate yield (entries 6 and 7). Various $\mathrm{Ni}(\mathrm{II})$ precatalysts were ineffective (entry 10).

Having identified optimized reaction conditions, we next explored the scope and limitations of this methodology by testing other representative alkenyl carboxylate (Scheme 2). Given that previous methods in the literature employing monodentate $\mathrm{N}\left(\mathrm{sp}^{2}\right)$ - or $\mathrm{O}\left(\mathrm{sp}^{2}\right)$-based directing groups are incompatible with internal alkenes, we were delighted to find that the present 1,2-diarylation reaction took place with both $E$ - and $Z$-configured alkenes, giving the final products $\mathbf{3 a}$ and $\mathbf{3 b}$ as single regio- and diastereoisomers, albeit in low yields. The reaction is highly sensitive to the alkene substitution pattern and the distance between the carboxylate and the al- kene, as 1,1-disubstituted, $\alpha$-substituted, and $\gamma, \delta$-unsaturated alkenes did not react well.

Scheme 2. Preliminary Alkene Scope ${ }^{a}$

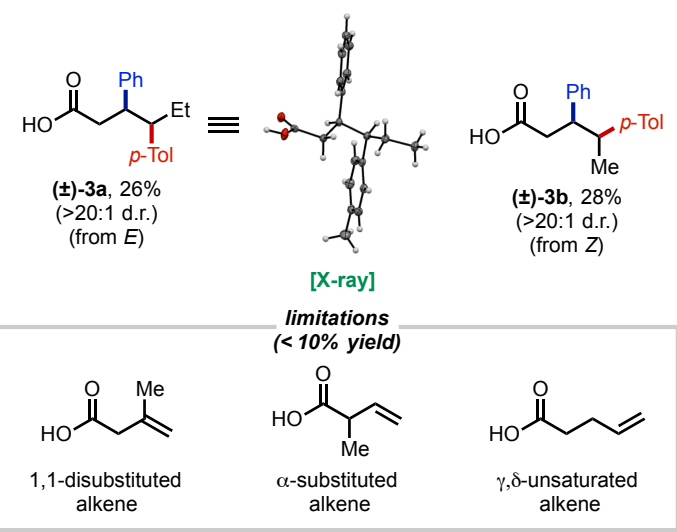

${ }^{a}$ Reactions performed on $0.1 \mathrm{mmol}$ scale. Percentages represent isolated yields.

We moved on to examine the electrophile scope of the reaction using $\mathrm{PhB}(\mathrm{nep})$ as the nucleophilic coupling partner (Table 2). Aryl iodides bearing electron-donating substituents in the para- and meta-positions reacted in good to excellent yields to deliver the desired products $(\mathbf{2} \mathbf{a}-\mathbf{2} \mathbf{j})$. Notably, aryl iodides containing $-\mathrm{Cl}$ and $-\mathrm{NHAc}$ groups were compatible in this reaction, allowing for potential downstream modification (2d and $\mathbf{2 f}$ ). Electron-withdrawing substituents resulted in diminished reactivity, but still delivered the desired products in moderate yields (2k and $\mathbf{2 1}$ ). In general, heterocyclecontaining and sterically hindered aryl iodides, alkenyl iodide, and alkynyl iodide coupling partners were incompatible under the optimized reaction conditions. 
Table 2. Electrophile and Nucleophile Scope ${ }^{a}$

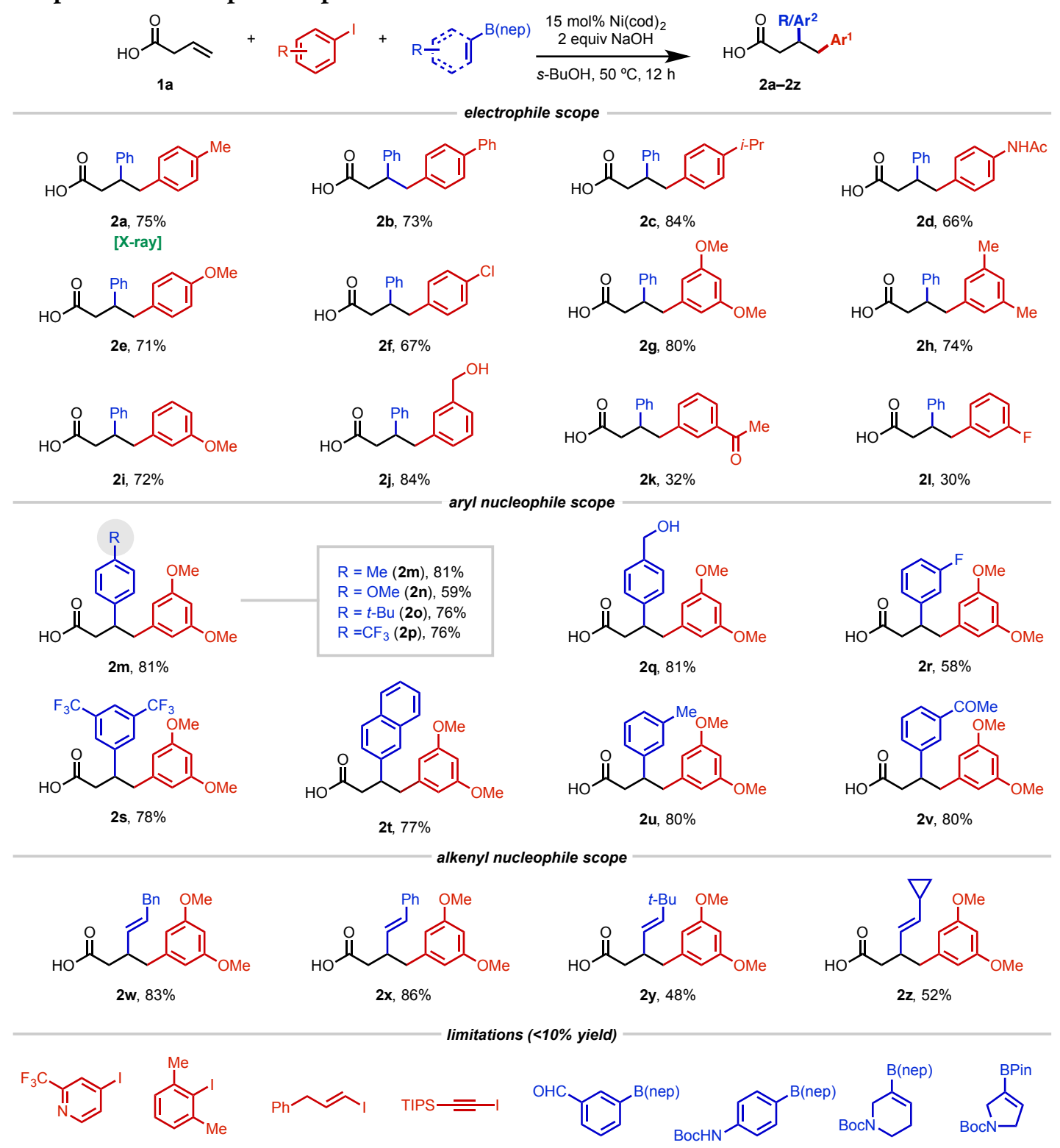

${ }^{a}$ Reactions performed on $0.1 \mathrm{mmol}$ scale. Percentages represent isolated yields.

Next, we investigated the nucleophile scope of the reaction using 1-iodo-3,5-dimethoxybenzene as the electrophilic component (Table 3). In general, a wide range of electron-rich and electron-poor $\mathrm{ArB}(\mathrm{nep})$ coupling partners performed well under optimized conditions, giving the desired products in good to excellent yield $(\mathbf{2} \mathbf{m}-\mathbf{2 v})$. Tethered alcohols and ketones could be tolerated in excellent yields ( $2 \mathbf{p}$ and $\mathbf{2 v}$ ). In order to expand the utility of this reaction platform, we wondered whether alkenyl B(nep) nucleophiles would be compat- ible toward 1,2-alkenylarylation. Gratifyingly, several alkenyl coupling partners were competent, delivering the corresponding 1,2-difunctionalized products in good to excellent yields $(\mathbf{2 w}-\mathbf{2 z})$. Notably, this reactivity allowed for the installation of styrenyl fragments that could be diversified downstream $(\mathbf{2 x})$, along with a vinyl cyclopropane motif $(\mathbf{2 z})$. Similar to the trend observed with aryl iodide coupling partners, heterocycle-containing $\mathrm{B}$ (nep) coupling partners were found to be incompatible at this stage of development. 


\section{Scheme 3. Product Diversification}

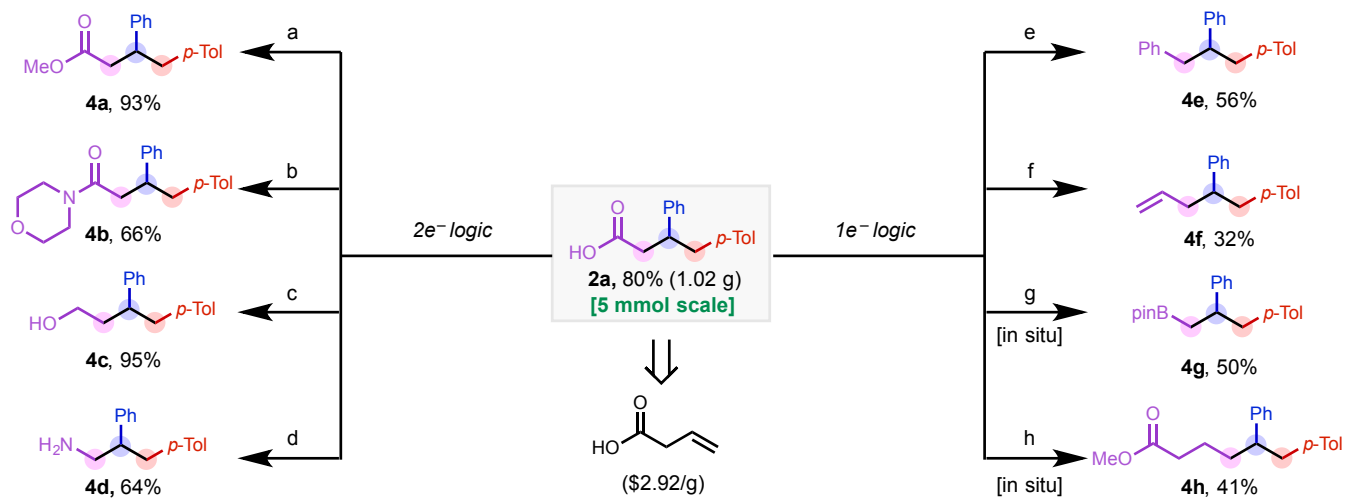

a) $12 \mathrm{M} \mathrm{HCl}$ (aq.), $\mathrm{MeOH}$, reflux. b) Morpholine, HATU, pyridine, DCM, $25{ }^{\circ} \mathrm{C}$. c) $\mathrm{LiAlH}_{4}$, anhydrous THF, $0{ }^{\circ} \mathrm{C}$ to $25^{\circ} \mathrm{C}$. d) (i) $\mathrm{DPPA}, \mathrm{Et} 3 \mathrm{~N}, t$ $\mathrm{BuOH}, 100{ }^{\circ} \mathrm{C}$; (ii) $6 \mathrm{M} \mathrm{HCl}$ e) (i) TCNHPI, DIC, $10 \mathrm{~mol} \% \mathrm{DMAP}, 1$,4-dioxane, $75{ }^{\circ} \mathrm{C}$; (ii) $20 \mathrm{~mol} \% \mathrm{NiCl}_{2} \cdot 6 \mathrm{H}_{2} \mathrm{O}, 20 \mathrm{~mol} \%$ bathophen, $\mathrm{PhB}(\mathrm{OH})_{2}, \mathrm{Et}_{3} \mathrm{~N}, 1$,4-dioxane/DMF, $75^{\circ} \mathrm{C}$. f) (i) TCNHPI, DIC, $10 \mathrm{~mol} \%$ DMAP, DCM, $25^{\circ} \mathrm{C}$; (ii) $10 \mathrm{~mol} \% \mathrm{Ni}(\mathrm{acac})_{2} \bullet \mathrm{xH}_{2} \mathrm{O}, 10 \mathrm{~mol} \% \mathrm{bipy}$, alkenyl zinc reagent, DMF, $25{ }^{\circ} \mathrm{C}$. g) (i) NHPI, DIC, $10 \mathrm{~mol} \%$ DMAP, DCM, $25^{\circ} \mathrm{C}$; (ii) $30 \mathrm{~mol} \% \mathrm{Cu}(\mathrm{acac})_{2}, \mathrm{~B}_{2} \mathrm{Pin}_{2}, \mathrm{LiOH}_{\bullet} \mathrm{H}_{2} \mathrm{O}, \mathrm{MgCl}_{2}, 1,4-$ dioxane/DMF, $25^{\circ} \mathrm{C}$. h) (i) NHPI, DIC, $10 \mathrm{~mol} \%$ DMAP, DCM, $25^{\circ} \mathrm{C}$; (ii) $20 \mathrm{~mol} \% \mathrm{Ni}\left(\mathrm{ClO}_{4}\right)_{2} \cdot 6 \mathrm{H}_{2} \mathrm{O}, \mathrm{Zn}, \mathrm{LiCl}$, methyl acrylate, $\mathrm{MeCN}, 25^{\circ} \mathrm{C}$.

In an effort to showcase the synthetic versatility of carboxylic acid directing group, we conducted a series of diversifications on standard product $\mathbf{2 a}$ (Scheme 2), which could be readily prepared on gram scale. Using the classical two-electron reactivity associated with carboxylic acid starting materials, we converted the difunctionalized products into the corresponding ester, amide, alcohol, and amine (4a-4d), enabling access to valuable bioactive substructures (vide infra). Additionally, viewing the carboxylic acid through the lens of one-electron synthetic logic, ${ }^{8,9}$ we examined several decarboxylative crosscoupling methods through the intermediacy of a redox-active ester. Indeed, decarboxylative arylation provided modular entry into 1,2,3-triarylpropane motifs (4e). Moreover, decarboxylative vinylation and borylation gave the corresponding products in moderate yield, effectively introducing functional handles for further modification ( $\mathbf{4 f}$ and $\mathbf{4 g}$ ). Finally, decarboxylative Giese addition provided $\delta, \varepsilon$-diarylated compound 4h, the product of a formal double homologation.

\section{Scheme 4. Applications of 1,2-Diarylation Reaction ${ }^{a}$}

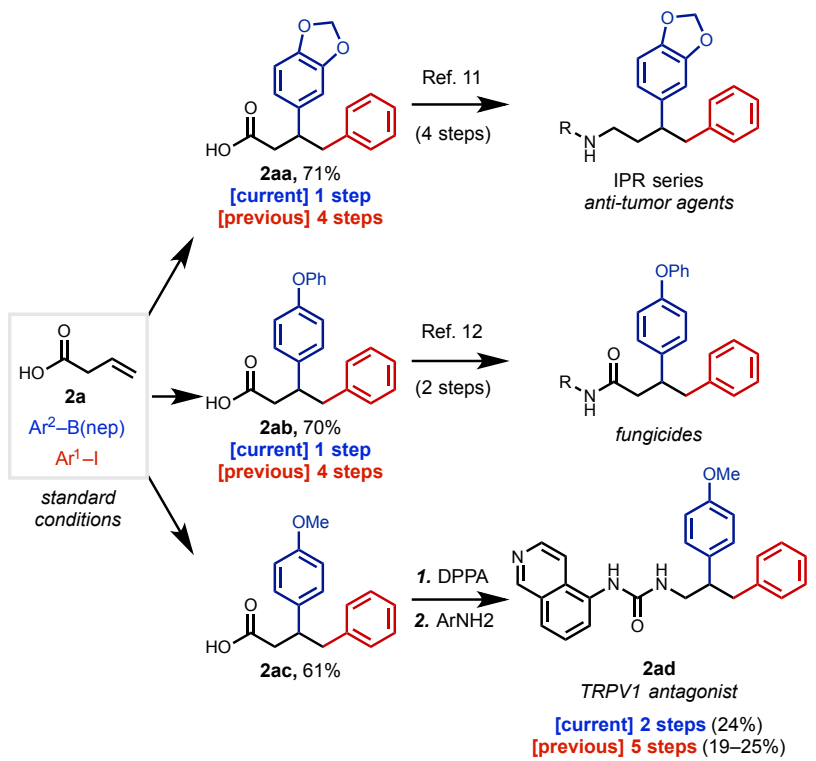

${ }^{a}$ Reactions performed on $0.1 \mathrm{mmol}$ scale. Percentages represent isolated yields.

To illustrate the utility of this carboxylate-directed alkene 1,2-diarylation in synthesis, we tested the method in several real-world scenarios involving biologically active target compounds containing a 1,2-diaryl motif (Scheme 4). Indeed, in the case of the IPR series of anti-tumor agents in breast cancer treatments, we could access the desired carboxylic acid intermediate $\mathbf{2 a a}$ in a single step in $71 \%$ yield compared to four steps in $33 \%$ yield. ${ }^{11}$ Similarly, carboxylic acid intermediate $2 \mathrm{ab}$ relevant to a family of fungicides was acquired in $70 \%$ in a single step. ${ }^{12}$ A third target, TRPV1 antagonist 2ad was synthesized in a 2-step sequence involving our developed reaction and an interrupted Curtius rearrangement. ${ }^{13}$ In addition to reducing the step count, our method offers a new divergent platform for probing structure-activity relationships in future industrial campaigns.

To gain insight into the reaction mechanism, we carried out a series of preliminary kinetic experiments. First, we compared the initial reaction rates of a series of arylboronates and aryl iodides with systematically varied electronic characteristics. In our earlier work with monodentate amide directing groups ${ }^{6}$, we found that electron-rich aryl iodides led to faster reaction rates and there was no influence of aryl boronate electronic properties on rate. In contrast, in the present system we observed no clear initial rate trends across either the aryl boronate or aryl iodide series (Figure 1). ${ }^{14}$

Figure 1. Hammett analysis of coupling partners in 1,2Diarylation Reaction.

\begin{tabular}{cccccc} 
& $p-\mathrm{OMe}$ & $p-\mathrm{Me}$ & $p-\mathrm{H}$ & $p-\mathrm{Cl}$ & $p-\mathrm{CF}_{3}$ \\
$\sigma$ value & -0.27 & -0.17 & 0.00 & 0.23 & 0.54 \\
\hline $\mathrm{Ar}-\mathrm{B}($ nep $)\left(k_{\text {rel }}\right)$ & 1.3 & 1.3 & 1.0 & 0.8 & 1.9 \\
$\mathrm{Ar}-\mathrm{l}\left(k_{\text {rell }}\right)$ & 2.4 & 0.5 & 1.0 & 1.5 & 1.1
\end{tabular}


The lack of clear electronic influence of both coupling partners eliminates many possibilities regarding the identity of the turnover-limiting step. One possibility is that the turnoverlimiting step changes as a function of the aryl group electronics. Alternatively, a step not involving either of the two aryl groups could be turnover-limiting, such as substrate binding or product dissociation. Additional details on this and other aspects of the reaction mechanism are currently under investigation in our lab.

In conclusion, we have demonstrated that a simple carboxylate group can be used to direct nickel-catalyzed 1,2diarylation of nonconjugated alkenes using aryl iodides and aryl boronates in the absence of an ancillary ligand. These products can be further manipulated to yield a wide range of valuable building blocks that would be difficult to synthesize using existing methods.

\section{ASSOCIATED CONTENT}

The Supporting Information is available free of charge on the ACS Publications website.

\section{AUTHOR INFORMATION}

\section{Corresponding Author}

*keary@scripps.edu

\section{Author Contributions}

${ }^{\dagger}$ J.D. and T. K. contributed equally.

\section{Notes}

The authors declare no competing financial interest.

\section{ACKNOWLEDGMENT}

This work was financially supported by Bristol-Myers Squibb (Unrestricted Grant), the National Science Foundation (CHE-1800280), the Alfred P. Sloan Fellowship Program, and the Camille Dreyfus Teacher-Scholar Program. We further acknowledge the NSF for a Graduate Research Fellowship (DGE-1346837, J.D.), the Kwanjeong Educational Foundation for a Graduate Fellowship (T.K.), and Dr. Art Olson and Shirley King for funding a high school internship (K.L.X.). We thank Professor Phil S. Baran for helpful discussions. We further thank Prof. Arnold L. Rheingold and Dr. Milan Gembicky (UCSD) for X-ray crystallographic analysis.

\section{REFERENCES}

(1) For representative reviews on alkene functionalization, see: (a) Saini, V.; Stokes, B. J.; Sigman, M. S. Transition-Metal-Catalyzed LaboratoryScale Carbon-Carbon Bond-Forming Reactions of Ethylene. Angew. Chem. Int. Ed. 2013, 52, 11206-11220. (b) Coombs, J. R.; Morken, J. P. Catalytic Enantioselective Functionalization of Unactivated Terminal Alkenes. Angew. Chem. Int. Ed. 2016, 55, 2636-2649.

(2) For representative reviews on conjunctive cross-coupling, see: (a) Derosa, J.; Tran, V. T.; van der Puyl, V. A.; Engle, K. M. Carbon-Carbon $\pi$-Bonds as Conjunctive Reagents in Cross-Coupling. Aldrichimica Acta 2018, 51, 21-32. (b) Giri, R.; KC, S. Strategies toward Dicarbofunctionalization of Unactivated Olefins by Combined Heck Carbometalation and Cross-Coupling. J. Org. Chem. 2018, 83, 3013-3022.
(3) (a) Stokes, B. J.; Liao, L.; de Andrade, A. M.; Wang, Q.; Sigman, M. S. A Palladium-Catalyzed Three-Component-Coupling Strategy for the Differential Vicinal Diarylation of Terminal 1,3-Dienes. Org. Lett. 2014, 16, 4666-4669. (b) Urkalan, K. B.; Sigman, M. S. Palladium-Catalyzed Oxidative Intermolecular Difunctionalization of Terminal Alkenes with Organostannanes and Molecular Oxygen. Angew. Chem. Int. Ed. 2009, 48, 3146-3149. (c) Kuang, Z.; Yang, K.; Song, Q. Pd-Catalyzed 1,2Diarylation of Vinylarenes at Ambient Temperature. Org. Chem. Front. 2017, 4, 1224-1228. (d) KC, S.; Dhungana, R. K.; Shrestha, B.; Thapa, S.; Khanal, N.; Basnet, P.; Lebrun, R. W.; Giri, R. Ni-Catalyzed Regioselective Alkylarylation of Vinylarenes via $\mathrm{C}\left(\mathrm{sp}^{3}\right)-\mathrm{C}\left(\mathrm{sp}^{3}\right) / \mathrm{C}\left(\mathrm{sp}^{3}\right)-\mathrm{C}\left(\mathrm{sp}^{2}\right)$ Bond Formation and Mechanistic Studies. J. Am. Chem. Soc. 2018, 140, 9801-9805. (e) Gao, P.; Chen, L.-A.; Brown, M. K. Nickel-Catalyzed Stereoselective Diarylation of Alkenylarenes. J. Am. Chem. Soc. 2018, 140, 10653-10657. (f) Catellani, M.; Chiusoli, G. P.; Concari, S. A New Palladium-Catalyzed Synthesis of cis,exo-2,3-Diarylsubstituted Bicycle[2.2.1] heptanes or Bicycle[2.2.1] hep-2-enes. Tetrahedron 1989, 45, 5263-5268. (g) Shaulis, K. M.; Hoskin, B. L.; Townsend, J. R.; Goodson, F. E.; Incarvito, C. D.; Rheingold, A. L. Tandem Suzuki CouplingNorbornadiene Insertion Reactions. A Convenient Route to 5,6Diarylnorbornene Compounds. J. Org. Chem. 2002, 67, 5860-5863. (h) Anthony, D.; Lin, Q.; Baudet, J.; Diao, T. Ni-Catalyzed Asymmetric Reductive Diarylation of Vinylarenes. Angew. Chem. Int. Ed. 2019, 58, 3198-3202.

(4) (a) Derosa, J.; Tran, V. T.; Boulous, M. N.; Chen, J. S.; Engle, K. M. Nickel-Catalyzed $\beta, \gamma$-Dicarbofunctionalization of Alkenyl Carbonyl Compounds. J. Am. Chem. Soc. 2017, 139, 10657-10660. (b) Shrestha, B.; Basnet, P.; Dhungana, R. K.; KC, S.; Thapa, S.; Sears, J. M.; Giri, R. Ni-Catalyzed Regioselective 1,2-Dicarbofunctionalization of Olefins by Intercepting Heck Intermediates as Imine-Stabilized Transient Metallacycles. J. Am. Chem. Soc. 2017, 139, 10653-10656. (c) Li, W.; Boon, J. K.; Zhao, Y. Nickel-Catalyzed Difunctionalization of Allyl Moities Using Organoboronic Acids and Halides with Divergent Reactivities. Chem. Sci. 2018, 9, 600-607. (d) Thapa, S.; Dhungana, R. K.; Magar, R. T.; Shrestha, B.; KC, S.; Giri, R. Ni-Catalysed Regioselective 1,2-Diarylation of Unactivated Olefins by Stabilizing Heck Intermediates as PyridylsilylCoordinated Transient Metallacycles. Chem. Sci. 2018, 9, 904-909. (e) Basnet, P.; Dhungana, R. K.; Thapa, S.; Shrestha, B.; KC, S.; Sears, J. M.; Giri, R. Ni-Catalyzed Regioselective $\beta, \delta$-Diarylation of Unactivated Olefins in Ketimines via Ligand-Enabled Contraction of Transient Nickelacycles: Rapid Access to Remotely Diarylated Ketones. J. Am. Chem. Soc. 2018, 140, 7782-7786. (f) Basnet, P.; KC, S., Dhungana, R. K.; Shrestha, B.; Boyle, T. J.; Giri, R. Synergistic Bimetallic Ni/Ag and $\mathrm{Ni} / \mathrm{Cu}$ Catalysis for Regioselective $\gamma, \delta$-Diarylation of Alkenyl Ketimines: Addressing $\beta$-Hydride Elimination by in Situ Generation of Cationic $\mathrm{Ni}$ (II) Catalysts. J. Am. Chem. Soc. 2018, 140, 15586-15590.

(5) (a) Derosa, J.; van der Puyl, V. A.; Tran, V. T.; Liu, M.; Engle, K. M. Directed, Nickel-Catalyzed 1,2-Dialkylation of Alkenyl Carbonyl Compounds. Chem. Sci. 2018, 9, 5278-5283. (b) van der Puyl, V. A.; Derosa, J.; Engle, K. M. Directed, Nickel-Catalyzed Umpolung 1,2Carboamination of Alkenyl Carbonyl Compounds. ACS Catal. 2019, 9, 224-229.

(6) (a) Derosa, J.; Kleinmans, R.; Tran, V. T.; Karunananda, M. K.; Wisniewski, S. R.; Eastgate, M. D.; Engle, K. M. Nickel-Catalyzed 1,2Diarylation of Simple Alkenyl Amides. J. Am. Chem. Soc. 2018, 140, 17878-17883. (b) Tran, V. T.; Li, Z.; Gallagher, T. J.; Derosa, J.; Liu, P.; Engle, K. M. ChemRxiv 2019, DOI: 10.26434/chemrxiv.7961633.

(7) For examples of chelating electrophiles in $\mathrm{C}\left(\mathrm{sp}^{3}\right)-\mathrm{C}\left(\mathrm{sp}^{3}\right)$ crosscoupling, see: (a) Owston, N. A.; Fu, G. C. Asymmetric Alkyl-Alkyl Cross-Couplings of Unactivated Secondary Alkyl Electrophiles: Stereoconvergent Suzuki Reactions of Racemic Acylated Halohydrins. J. Am. Chem. Soc. 2010, 132, 11908-11909. (b) Wilsily, A.; Tramutola, F.; Owston, N. A.; Fu, G. C. New Directing Groups for Metal-Catalyzed Asymmetric Carbon-Carbon Bond-Forming Processes: Stereoconvergent Alkyl-Alkyl Suzuki Cross-Couplings of Unactivated Electrophiles. J. Am. Chem. Soc. 2012, 134, 5794-5797.

(8) Smith, J. M.; Harwood, S. J.; Baran, P. S. Radical Retrosynthesis. Acc. Chem. Res. 2018, 51, 1807-1817. 
(9) For examples of decarboxylative cross-coupling using redox-active esters, see: (a) Cornella, J.; Edwards, J. T.; Qin, T.; Kawamura, S.; Wang, J.; Pan, C.-M.; Gianatassio, R.; Schmidt, M. A.; Eastgate, M. D.; Baran, P. S. Practical Ni-Catalyzed Aryl-Alkyl Cross-Coupling of Secondary Redox-Active Esters. J. Am. Chem. Soc. 2016, 138, 2174-2177. (b) Li, C.; Wang, J.; Barton, L. M.; Yu, S.; Tian, M.; Peters, D. S.; Kumar, M.; Yu, A. W.; Johnson, K. A.; Chatterjee, A. K.; Yan, M.; Baran, P. S. Decarboxylative Borylation. Science 2017, 356, eeam7355. (c) Edwards, J. T.; Merchant, R. R.; McClymont, K. S.; Knouse, K. W.; Qin, T.; Malins, L. R.; Vokits, B.; Shaw, S. A.; Bao, D.-H.; Wei, F.-L.; Zhou, T.; Eastgate, M. D.; Baran, P. S. Decarboxylative Alkenylation. Nature 2017, 545, 213-218. For examples of carboxylate/carboxamide-directed $\mathrm{C}\left(\mathrm{sp}^{3}\right)-\mathrm{H}$ activation followed by decarboxylative coupling, see: (d) Beck, J. C.; Lacker, C. R.; Chapman, L. M.; Reisman, S. E. A Modular Approach to Prepare Enantioenriched Cyclobutanes: Synthesis of (+)-Rumphellaone A. Chem. Sci. 2019, 10, 2315-2319. (e) Shang, M.; Feu, K. S.; Vantourout, J. C.; Barton, L. M.; Osswald, H. L.; Kato, N.; Gagaring, K.; McNamara, C. W.; Chen, G.; Hu, L.; Ni, S.; Fernández-Canelas, P.; Chen, M.; Merchant, R. R.; Qin, T.; Schreiber, S. L.; Melillo, B.; Yu, J.-Q.; Baran, P. S. Modular, Stereocontrolled $\mathrm{C}_{\beta}-\mathrm{H} / \mathrm{C}_{\alpha}-\mathrm{C}$ Activation of Alkyl Carboxylic Acids. Proc. Natl. Acad. Sci. U. S. A. 2019, 116, 8721-8727.

(10) For examples of palladium-catalyzed carboxylate-directed reactions, see: (a) Giri, R.; Maugel, N.; Li, J.-J.; Wang, D.-H.; Breazzano, S. P.; Saunders, L. B.; Yu, J.-Q. Palladium-Catalyzed Methylation and Arylation of $\mathrm{sp}^{2}$ and $\mathrm{sp}^{3} \mathrm{C}-\mathrm{H}$ Bonds in Simple Carboxylic Acids. J. Am. Chem. Soc. 2007, 129, 3510-3511. (b) Huffman, T. R.; Wu, Y.; Emmerich, A.; Shenvi, R. A. Intermolecular Heck Coupling with Hindered Alkenes
Directed by Potassium Carboxylates. Angew. Chem. Int. Ed. 2019, 58, 2371-2376.

(11) Wang, F.; Li, J.; Sinn, A. L.; Knabe, W. E.; Khanna, M.; Jo, I.; Silver, J. M.; Oh, K.; Li, L.; Sandusky, G. E.; Sledge, G. W., Jr.; Nakshatri, H.; Jones, D. R.; Pollok, K. E.; Meroueh, S. O. Virtual Screening Targeting the Urokinase Receptor, Biochemical and Cell-Based Studies, Synthesis, Pharmacokinetic Characterization, and Effect on Breast Tumor Metastasis. J. Med. Chem. 2011, 54, 7193-7205.

(12) In the following reference, no yield was reported for the four-step sequence to access 2ab: Lee, S. H.; Kim, I.-O.; Cheong, C. S.; Chung, B. Y. Synthesis and Antifungal Activities of N-Aryl-4-phenyl-3-(4phenoxyphenyl)butanamides. Arch. Pharm. Chem. Life Sci. 1999, 332, 333-336.

(13) Jetter, M. C.; Youngman, M. A.; McNally, J .J.; McDonnel, M. E.; Zhang, S.-P.; Dubin, A. E.; Nasser, N.; Codd, E. E.; Flores, C. M.; Dax, S. L. Heteroaryl $\beta$-tetralin Ureas as Novel Antagonists of Human TRPV1. Bioorg. Med. Chem. Lett. 2007, 17, 6160-6163.

(14) Though electron-rich aryl iodides typically provide higher yields, electron-poor aryl iodides react with similar rates. Low yield in these cases is attributed to increased formation of uncharacterized byproducts. 
Insert Table of Contents artwork here

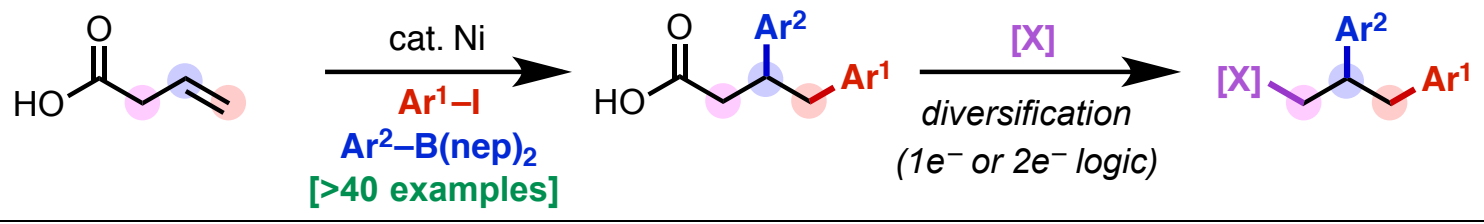

